\title{
O RECINTO SAGRADO: EDUCAÇÃO E ANTIRRACISMO NO BRASIL
}

\section{PETRÔNIO DOMINGUES}

Professor do Departamento de História da Universidade Federal de Sergipe pjdomingues@yahoo.com.br

\section{RESUMO}

A proposta deste artigo é apresentar alguns aspectos das fases de atuação do movimento negro brasileiro no campo educacional depois da abolição da escravatura. A ideia central é mostrar que, para esse movimento, a educação é considerada um instrumento de importância capital para enfrentar o racismo e garantir a integração e prosperidade do negro na sociedade brasileira. NEGROS - EDUCAÇÃO - RELAÇÕES RACIAIS

\footnotetext{
ABSTRACT

THE SACRED ROOM: EDUCATION AND THE STRUGGLE AGAINST RACISM IN BRAZIL. This article intends to present some aspects of the periods of activity of the Brazilian black movement in the field of education after the abolition of slavery. Its core idea is to show that this movement considers education to be an instrument of utmost importance to face racism and guarantee the integration and prosperity of blacks in Brazilian society.

BLACKS - EDUCATION - RACIAL RELATIONSHIP
} 
A escola é o recinto sagrado onde vamos em comunhão buscar as ciências, artes, música etc. '

Em livro de memórias, José Correia Leite (1992) relata sua trajetória de vida na São Paulo da Belle Époque. Filho de uma "negra doméstica" (que acabou sofrendo problemas mentais) e nascido em 1900, esse afro-paulista levou a infância e adolescência na penúria, similar à de um menor abandonado, sem maiores perspectivas de futuro, sem conhecer o pai e privado de afeto e carinho. Enfrentando uma série de dificuldades para sua subsistência diária, trabalhou como entregador de marmitas, menino de recados e ajudante de carpintaria. Morava numa casa de pau-a-pique no bairro do Bixiga, numa rua habitada por negros e portugueses. Ávido por alfabetizar-se, ingressou numa pequena escola particular. Como não tinha condições de pagar a mensalidade, prestava serviços de limpeza para a proprietária do estabelecimento. Foi a primeira escola em que entrou. Radiante, começou entusiasmado com o "livro de $A B C$ " dado pela professora, mas não demorou muito, pois a escola foi fechada. Quase tudo voltou à estaca zero e não havia aprendido a ler e escrever. Era uma situação frustrante. Lembra que quando conheceu Jayme de Aguiar, um adolescente negro que estudava no colégio Coração de Jesus, sua frustração aumentou: "Eu ficava às vezes despeitado com aquilo, porque ele interrompia a brincadeira para se arrumar e ir para a escola. Saía todo de colarinho engomado... [E] eu continuava naquela situação de não poder". Descobriu que a maçonaria mantinha escolas para "meninos impossibilitados de pagar". Ingressou numa delas, mas demorou pouco, já que a escola também fechou suas portas. Mais tarde, fez um curso de alfabetização oferecido por um abade do Mosteiro de São Bento. A escola era destinada a jornaleiros, mas, como ninguém sabia de sua procedência, apresentou-se como tal e conseguiu se matricular. Aprendeu mais um pouco, porém, como declara, "nunca chegava a aprender o suficiente para dizer que sabia ler e escrever". Perseverante, não

I. Esta epígrafe faz parte de um artigo intitulado "Instrução". Escrito por uma liderança afropaulista, foi publicado no jornal da imprensa negra O Clarim, São Paulo, 3/2/1924, p.2. Sobre os jornais publicados por negros no pós-abolição e destinados a tratar de suas questões, ver Domingues (2008), especialmente o primeiro capítulo. 
desistiu do sonho, mas teve de postergá-lo. Começou a participar dos bailes e dos clubes negros, o que the deu um novo alento, mesmo ciente, lembra ele, "que não podia ser bem falante por causa da minha pouca instrução". Um dia reencontrou Jayme de Aguiar, já um assíduo frequentador dos bailes e clubes negros, e percebeu que algo o incomodava no antigo amigo: "O Jayme de Aguiar, em todo nosso encontro, punha a mão no bolso e tirava um soneto e lia pra eu ouvir. E, o que eu entendia de soneto? Outras vezes tirava uma crônica que ele não tinha onde publicar e lia também". Ou seja, Correia Leite, por ser "pouco alfabetizado", sentia-se humilhado quando o amigo demonstrava o domínio dos códigos de letramento. Um dia Aguiar lhe perguntou se não queria tomar "umas aulas de português", a que Correia Leite respondeu afirmativamente. $\bigcirc$ amigo, então, passou a ir duas vezes por semana em sua casa, para Ihe ensinar matemática e português, até que "começou a melhorar", isto é, deixou de ser, definitivamente, um analfabeto funcional (Leite, 1992, p.23-29), situação que lhe permitiu se tornar fundador, junto com Jayme de Aguiar, do jornal O Clarim e se notabilizar, anos depois, como uma das principais lideranças do "movimento associativo dos homens de cor".

Afonso Henriques de Lima Barreto foi outro afro-brasileiro que sentiu na pele as consequências das desigualdades raciais na educação. Em seu caso, o nó górdio não foi a alfabetização e sim a conclusão do curso superior. Filho de um tipógrafo e de uma professora, Lima Barreto - como ficou celebrizado na literatura brasileira - nasceu em I88I, no Rio de Janeiro. Foi alfabetizado pela mãe, mas, com o falecimento desta, entrou para a escola pública em I888, ano em que assistiu com seu pai à assinatura da Lei Áurea e às festas populares de comemoração da abolição da escravatura. Sob a tutela do padrinho, o visconde de Ouro Preto, estudou no Liceu Popular Niteroiense e, em 1895, prestou os primeiros exames no Ginásio Nacional. Um ano depois, matriculou-se no Colégio Paula Freitas, no Rio de Janeiro. Frequentou o curso preparatório à Escola Politécnica - a instituição de formação de engenheiros localizada no Largo de São Francisco, no centro do Rio -, sendo aprovado no exame de ingresso em 1 897. Todavia, não conseguiu se diplomar, o que lhe gerou grande frustração. Talvez tenha sido por isso que Lima Barreto passou a nutrir um sentimento de rancor contra os "doutores" e seus privilégios. Como ele próprio escreveu: "No Brasil, o doutor (e olhem que eu escapei de ser doutor), é um flagelo, porque se transformou em nobreza [...]. O doutor, se é ignorante, o é; mas sabe; o 
doutor, se é preto, o é, mas... é branco" (Barreto, 1956, p.9I). Percebe-se, aqui, como o genial escritor carioca foi irônico ao confessar ter "escapado de ser doutor". Irônico porque tinha plena consciência que a imagem consagrada do "doutor" é aquela de pessoa que "sabe" e "é branco", não havendo, assim, possibilidade de se referir a um "preto". Em seus relatos, há diversas passagens em que ele faz alusão às tensões raciais e melancolias vividas como estudante afro-brasileiro e pobre, desde 1897, quando foi aprovado no processo seletivo e ingressou na Escola Politécnica, até 1903, quando abandonou o sonho de tornar-se doutor, após consecutivas reprovações em disciplinas do curso e, também, depois da doença do pai - que sofreu problemas mentais e foi declarado inválido - e da traumática mudança para o subúrbio de Todos os Santos com a família. A trajetória de Lima Barreto é, sem dúvida, um bom indicador de que, pelas trilhas da educação, a porta de entrada para o título de doutor estava obstruída para os afro-brasileiros nas primeiras décadas do período do pós-abolição.

Liderando as estatísticas em matéria de evasão escolar, repetência e analfabetismo, os negros no Brasil têm passado por uma miríade de dificuldades na área educacional. Quando comparados aos brancos, também levam desvantagens quanto ao ingresso, à progressão e conclusão no ensino fundamental e médio (Hasenbalg, Silva, 1990; Telles, 2003). Porém, esse círculo vicioso não é novo. Desde a época da escravidão, o negro enfrentava obstáculos nessa área. Vale lembrar que a Constituição de 1824 - a primeira do país - não garantia a prerrogativa da cidadania aos escravos, de modo que eles sequer eram alfabetizados. Talvez isso ocorresse porque os senhores tinham noção de que saber ler e escrever era uma ferramenta que, nas mãos dos escravos, poderia ser manejada em prol de sua liberdade.

Com efeito, a historiografia mais recente tem demonstrado que, mesmo sob condições adversas, os negros foram sujeitos de seu devir e procuraram explorar em proveito próprio aspectos do sistema escravista. Em I853, o professor Pretextato dos Passos e Silva - um homem "preto", conforme autodesignação - criou uma pequena escola de instrução primária para "meninos de cor" na Corte, sob a justificativa de que os pais dos alunos brancos das escolas ou colégios não toleravam a convivência de seus filhos com os "pretos", por isso os professores não admitiam tais crianças e, quando o faziam, não as acolhiam bem. Funcionando a princípio na casa do professor Pretextato Silva 
e reunindo ao menos quinze alunos, a escola ensinava "leitura, doutrina, as quatro operações da aritmética e escrita". Otimista, Adriana Maria Paulo da Silva postula a hipótese de essa experiência educacional "ter sido uma, entre várias outras experiências semelhantes, de cuja historicidade nós só temos fragmentos e pistas" (Silva, 2000, p. 131 ).

Em 28 de setembro de 187I, foi aprovada a Lei do Ventre Livre. Estabelecia que, a partir dessa data, os filhos de escravos que nascessem no Império seriam considerados livres. Tais crianças ficariam com os pais até a idade de oito anos, quando os senhores de escravos poderiam entregá-las às instituições estatais e receber uma indenização, ou mantê-las consigo até os vinte anos, utilizando seus serviços como forma de retribuição pelos gastos que tiveram com seu sustento. No caso das crianças negras que foram entregues às instituições estatais, houve iniciativas da parte do governo ou de certos setores das elites que procuravam oferecer-Ihes educação básica (Fonseca, 2002). Não se deve, entretanto, superestimar a importância dessas iniciativas que, além de serem deficientes do ponto de vista educacional, jamais se universalizaram.

Em 1878, o governo do Império realizou uma reforma no sistema de ensino, estabelecendo, por meio de decreto, que poderiam se matricular nos cursos noturnos todas as pessoas do sexo masculino, livres ou libertos, maiores de quatorze anos. Ao pesquisar os cursos noturnos de instrução primária da Biblioteca Pública Pelotense - BPP -, iniciados em 1877, Eliane Peres notou um "silêncio" das fontes no tocante ao perfil étnico-racial da "clientela". Depois de trilhar um longo caminho e cruzar alguns nomes de alunos com as diretorias de associações e entidades populares de Pelotas (RS), a pesquisadora comprovou a presença dos negros em tais cursos, embora reconheça os "limites" de seu procedimento metodológico, uma vez que abrangeu "um número restrito de sujeitos" (Peres, 2002, p.80). Ademais, os benefícios do decreto de 1878 não se estendiam aos escravos. Se as aulas da BPP podiam ser frequentadas por negros, eram apenas por livres ou libertos.

Em Cachoeira, na Bahia, o professor abolicionista Cincinatos França manteve, durantes anos, uma escola noturna para a alfabetização de libertos. Em 1889, "mais de 50 alunos frequentavam as salas de aula do professor Cincinatos, entre eles alguns ganhadores e canoeiros que migraram dos canaviais" (Fraga Filho, 2006, p.352). Apesar dos avanços, havia uma distância nada desprezível entre o dispositivo legal de 1878 e a prática social. Muitos 
negros livres e libertos de Pelotas, de Cachoeira e de outros rincões do país continuaram sendo proscritos da educação pública ou privada. Os sinais de mudança somente se aprofundaram com a abolição da escravatura, em I 888, e a implantação da República, em 1889.

A finalidade deste artigo é apresentar alguns elementos das fases de atuação do chamado "movimento associativo dos homens de cor", no campo educacional depois da supressão do cativeiro no Brasil. A ideia central é mostrar que a educação sempre esteve presente na agenda desse movimento, sendo concebida como um recurso de importância capital para se contrapor ao "preconceito de cor" e garantir a inclusão e prosperidade do afro-brasileiro na sociedade. Na primeira e segunda fase, as atenções do também denominado "movimento negro" se dirigiram ao ensino fundamental; na terceira fase o eixo das preocupações passou a ser o ensino superior e, especialmente, a construção de uma educação fundada no respeito à diversidade étnico-racial. Quanto à periodização das fases aqui sugerida, não é aleatória, tendo sido estabelecida levando em consideração o próprio desenvolvimento do movimento, que, por sua vez, reflete as várias conjunturas políticas, sociais, culturais e econômicas pelas quais tem passado o país.

\section{PROTESTO NEGRO E EDUCAÇÃO}

\section{Primeira fase (1889-1937)}

Será que a nova ordem político-social do pós-abolição garantiu o acesso imediato do negro à escola? Todas as evidências indicam que não. Como assinala George Reid Andrews, os "afro-brasileiros" passaram a viver em estado de exclusão nesse momento. Eram excluídos, seja politicamente em decorrência das limitações da República no que se refere ao sufrágio e a outras formas de participação política; "seja social e psicologicamente, em face das doutrinas do racismo científico e da 'teoria do branqueamento'; seja ainda economicamente, devido às preferências em termos de emprego em favor dos imigrantes europeus" (Andrews, 1991, p.32). No campo educacional, a situação não foi diferente. $O$ negro se manteve afastado dos bancos escolares ou quando teve acesso a eles foi com muitas dificuldades. Em I 893, O Exemplo, jornal da imprensa negra do Rio Grande do Sul, em 8/I/I893, noticiava em primeira 
página: "Acaba de vir ao nosso conhecimento que algumas escolas públicas da capital recusam abertamente admitir ao ensino crianças de cor, outras que, limitando o número destas, mesmo assim maltratam-nas, a ponto de seus pais, em justa indignação retirarem-nas das aulas".

Para reagir a esse quadro de preterições e discriminações raciais, de um lado, e reforçar o espírito de união, solidariedade e autodeterminação, de outro, um grupo de "pessoas de cor" investiu na construção de uma série de associações, com perfis distintos: clubes, entidades beneficentes, grêmios literários, centros cívicos, jornais e até mesmo organizações políticas. Em São Paulo, apareceram a Sociedade Cooperativa dos Homens de Cor, em 1902, o Centro Cultural Henrique Dias, em 1908, a Sociedade União Cívica dos Homens de Cor, em 1915; no Rio de Janeiro, o Centro da Federação dos Homens de Cor; em Pelotas (RS), a Sociedade Progresso da Raça Africana, em 1891; em Lages (SC), o Centro Cívico Cruz e Souza, em 1918. De caráter notadamente cívico, cultural ou recreativo, as agremiações do movimento associativo dos "homens de cor" - como se dizia na época - exerceram um importante papel de conscientização e mobilização da população de ascendência africana (Silva, 2000, p. |38-139).

Do ponto de vista educacional, tais associações denunciavam o analfabetismo e a precariedade da escolarização da "população de cor". Mas não ficaram apenas no plano da denúncia. Muitas delas empreenderam algum tipo de ação educativo-cultural em suas dependências, como apresentações musicais, encenações teatrais, saraus, sessões de recitais de poesias, cursos, palestras. Havia as que mantinham aulas noturnas e bibliotecas. Foi o caso da Feliz Esperança, na cidade de Pelotas. Desde o final da década de 1880, essa associação era considerada um "baluarte da representação negra", condição que manteve até sua extinção, por volta de 1917 (Loner, 2008).

Associações negras também abriram escolas, sendo que uma delas a Sociedade Amigos da Pátria, de São Paulo, fundada em 13 de maio de 1908 , era dirigida por Salvador Luís de Paula, um negro ex-ativista do movimento abolicionista. A escola chamava-se Progresso e Aurora. Não se têm maiores detalhes de sua dinâmica interna. Contudo, o jornal paulista Progresso, em 23/9/1929, p.7, informava que a escola era "mista" e atendeu "mil e tantas pessoas" durante "dez anos", o que permite supor que Progresso e Aurora foi talvez o estabelecimento de ensino voltado para a "população de cor" de 
maior longevidade na capital paulista, durante as primeiras décadas do século $X X$. Por dificuldades financeiras, encerrou suas atividades.

O Clube 13 de Maio dos Homens Pretos, fundado em São Paulo no dia 20 de julho de 1902, previa o amparo educacional aos seus associados desde os estatutos ${ }^{2}$. Todavia, a agremiação somente reuniu forças e recursos para consubstanciar a antiga aspiração décadas depois. Em 28/9/1930, p.4, Progresso noticiava a mudança de sede do Clube 13 de Maio e, no meio da notícia, informava: "além de proveitosas reuniões diárias onde serão ventilados os magnos assuntos da raça, sabemos que o 'Treze' vai manter uma escola, não só para os filhos de seus sócios, como para a alfabetização daqueles que trabalham durante o dia".

Em Campinas, a Federação Paulista dos Homens de Cor tinha como horizonte a promoção do auxílio mútuo, mas se diferenciava das demais sociedades do gênero pela especificidade de seu público-alvo. Nos seus estatutos dispunha-se a labutar em prol do desenvolvimento "moral e intelectual dos negros do Brasil". Para tanto, vislumbrava ser necessário, entre outras medidas, velar pela educação dos sócios, proporcionando-lhes aula de alfabetização em períodos diurnos e noturnos. Entrementes, esse ideário educacional não saiu do papel, até que, em 1910, a agremiação incorporou o Colégio São Benedito, nascido cinco anos antes ${ }^{3}$.

2. Eis o extrato dos estatutos da agremiação: "O Club 13 de Maio dos Homens Pretos, fundado nesta capital em 20 de julho de 1902, tem por fim: a) festejar anualmente, com o brilhantismo possível, a gloriosa data de 13 de maio de 1888; b) criar escolas noturnas e diurnas, quando seus fundos o permitirem; c) criar uma biblioteca para os sócios; d) criar fundos de beneficência para os sócios e suas famílias; e) realizar conferências na sede social, versando as mesmas sobre instrução e educação, com a assistência de famílias". (Diário Oficial do Estado de São Paulo, n. 234, 22/10/1902, p.2245).

3. Colégio São Benedito era dedicado mormente às crianças negras e pobres, mas aceitava alunos de todas as cores, de 6 a 15 anos, e funcionava em regime de internato e semiinternato, dividindo-se em duas seções, uma masculina e outra feminina. Suas aulas ocorriam num único horário, das II horas às I5h30. A matrícula era gratuita, não obstante os alunos pagavam mensalidades, o que lhes davam direito a alimentação, livros e material escolar. Para os alunos órfãos e desvalidos, era assegurada não só a isenção no pagamento da matrícula, como ainda no dos livros e material escolar. Em fins de 1907, o colégio terminou o ano letivo com 42 I alunos, sendo 359 do sexo masculino e 62 do sexo feminino. No masculino, havia 9 turmas, sendo 2 de primeiro ano, I de segundo, I de terceiro, 2 de quarto, 2 de quinto e I de sexto ano. No feminino havia 6 turmas, sendo uma de cada ano. Em 1909, o colégio atravessava uma fase de sérias dificuldades financeiras, quando recebeu a visita de doutor 
Em Porto Alegre, o grupo de negros ligados ao jornal O Exemplo edificou uma escola noturna em 1902, tendo por meta estruturá-la com ensino primário, médio e secundário. No ensino primário, o programa curricular previa a leitura, escrita, aritmética e gramática; no ensino médio, português, gramática, aritmética, geometria prática, geografia e ciências; já no ensino secundário, previa-se o estudo de línguas e de matemática. A escola aprovou um regulamento de caráter democrático. Seriam admitidos todos os indivíduos, independentemente de cor, sexo, nacionalidade, crença religiosa ou profissão. Sua direção seria colegiada, aberta a todos os professores e representantes de associações que contribuíssem naquela empreitada. Não seria cobrada, em hipótese alguma, taxa de mensalidade. Para manter a escola noturna $O$ Exemplo, seus dirigentes conclamavam a colaboração das associações negras, doações e subscrições populares. Não se sabe por quanto tempo vigeu essa instituição, tampouco se tem uma noção da quantidade de alunos que atendeu. Porém, essa foi possivelmente a experiência de maior vitalidade de uma escola cuja grande preocupação era atender aos negros de Porto Alegre no início do século XX (Müller, 1999).

De 1926 a 1929, o Centro Cívico Palmares cerrou fileiras nas lides contra o "preconceito de cor", em São Paulo, e uma de suas profícuas iniciativas foi a instituição de uma escola que, à luz das demais do gênero, tinha uma estrutura pedagógica um pouco mais sólida. "De seu curso secundário que contava com um afinado corpo docente preto", noticiava, em 24/3/1929, p.2, o jornal Progresso, "existem alunos nas escolas superiores do país". Não se sabe se esta notícia procede, pois nenhuma outra fonte atestou a existência ali de um "curso secundário". O certo é que a escola funcionava na sede do centro com aulas no período diurno e noturno. Ensinava-se a ler, escrever e contar, bem como gramática, geografia, história, aritmética, geometria, entre outras disciplinas. Mantendo ainda uma biblioteca e sediando palestras de cunho cultural, o Centro Cívico Palmares reverberou o amadurecimento do "movimento associativo" dos afro-paulistas.

Monteiro Lopes, deputado federal pelo antigo Distrito Federal - atual Rio de Janeiro. Ao ficar a par da situação, o deputado negro ficou sensibilizado e prometeu esforçar-se na Câmara dos Deputados para ajudar o estabelecimento de ensino. Em 30 de abril de 1910, o Colégio São Benedito foi anexado à Federação Paulista dos Homens de Cor, mas manteve uma diretoria autônoma (Pereira, 200 I, p.5 I-7I). 
Cientes de que eram necessárias ações concretas, mas também críticos da falta de compromisso dos gestores públicos para proporcionar-lhes pelo menos os estudos básicos, as lideranças das associações negras tomaram para si a responsabilidade de conscientizar a população de ascendência africana dos benefícios provenientes da "instrução". O jornal da imprensa negra $O$ Clarim, em 3/2/1924, p.2, bradava: "Oh pais! Mandai vossos filhos ao templo da instrução intelectual - 'a escola', não os deixes analfabetos como dantes". Com retórica sentimental, o líder afro-paulista Horácio da Cunha fazia em 0 Clarim d'Alvorada, de 24/2/1926, p.5, apelo parecido: "Que pesar eu sinto no coração, quando ouço de um moço ou moça de cor, esta resposta: não sei ler. Patrícios meus! Mandai vossos filhos às escolas"4. $\bigcirc$ "patrício" Eusébio de Oliveira, em Progresso, de 30/4/I 932, p.2, aumentava a cantilena:

Escolas, e sempre escolas é que devemos reclamar, gritar, e exigir dos nossos governantes, por que por ela e nela tornar-nos-emos homens dignos, respeitados e altaneiros. A escola nos dá o ensinamento preciso para sermos o cidadão consciente de nossas prerrogativas e deveres sociais, ao par da consciosidade [sic] de nossos direitos pátrios e legais. A escola conduzir-nos-á ao apogeu da civilização e intelectualidade, por que a nossa inteligência é lúcida, precisando apenas instruí-la e educá-la suficientemente. [...] A escola nos chama, meus patrícios. Vamos para ela.

Nessa jornada de sensibilização, as mulheres negras não ficaram alheias, nem desempenhavam um papel decorativo ou simbólico, mas foram proativas, seja se aliando aos "homens de cor", seja assumindo iniciativas autônomas, como a que foi noticiada pelo jornal O Exemplo, em 6/2/1910, p.2:

4. Dois anos depois, em 23/6/1928, p. I, Horácio da Cunha voltava a traçar um diagnóstico do problema educacional do negro em tom professoral, mas, desta feita, no jornal Progresso: "Vemos, todos os dias, pelas ruas da nossa capital, grande número de meninos pretos em abandono. [...] Já vamos para quatro décadas que somos livres, filhos da terra de Santa Cruz e, ainda, não temos um rancho, ao menos, onde se ministre as primeiras letras aos nossos irmãos na cor!... Que fazer? Vontade? Essa deusa, felizmente não nos falta, mas... Suprindo a falta da escola que carecemos, aí está o Juízo de Menores, preparando homens válidos e capazes para o futuro. Abreviar o estafante serviço dessa autoridade, precisamos. Como? Educando os nossos filhos. Se assim procedermos, jamais escapará de seus lábios: '- Sou um analfabeto'". 
Sabemos que um grupo de senhoritas e senhoras constituídas numa grande comissão, dirigirão um apelo à todas as nossas associações no sentido de cada uma delas estabelecer aulas noturnas e a criação de bibliotecas instrutivas, para as associadas e seus filhos. Da aludida comissão que se baterá pelo levantamento intelectual e moral dos nossos homens, será presidente a distinta jovem Dulcina S. das Dores.

Das associações de recorte racial dessa fase, a Frente Negra Brasileira ( 193 | - 1937) foi a que amealhou maior grau de organização e estruturação, sendo, sem sombra de dúvida, a mais importante. Ela se destacou pelo tempo em que permaneceu ativa, pelo número de adeptos, pelas realizações e, também, pela quantidade de atividades que desenvolveu. A Frente Negra Brasileira - FNB - se expandiu em ritmo acelerado, reunindo no seu apogeu mais de sessenta "delegações" (sucursais) distribuídas pelo interior de São Paulo e por outros Estados, como Rio de Janeiro, Minas Gerais, Espírito Santo, além de inspirar o soerguimento de agremiações homônimas em Pelotas, Salvador e Recife. Sua organização político-administrativa era complexa e diversificada. Havia centralização do poder e predominava uma rígida estrutura hierárquica (Pinto, 1993; Domingues, 2005). Para impulsionar os projetos específicos, a FNB instituiu e animou vários departamentos, sendo o maior e mais importante o de Instrução, também chamado Departamento de Cultura ou Intelectual, responsável pela área educacional da agremiação.

Convém observar que o conceito de educação articulado pelo movimento negro naquela fase era amplo, compreendendo tanto a escolarização quanto a formação cultural e moral do indivíduo. A palavra "educação" era usada frequentemente com esses dois sentidos. Já a palavra "instrução" tinha um sentido mais específico: de alfabetização ou escolarização. A "instrução" foi uma das questões mais pautadas da FNB. Em quase todas as edições do jornal da frente, A Voz da Raça, encontra-se alusão ao quadro de carência educacional da população negra e à necessidade de ela se instruir.

p primeiro grande projeto do departamento de Instrução foi a criação de um curso de alfabetização, em 1932. Era, em princípio, destinado a todos os negros ("menores e adultos"), associados ou não à entidade, no período noturno. A partir de 1934, a FNB passou a oferecer também o curso primário. Marcelino Felix (200I) sugere que o curso tinha duração de três anos, adotava 
um sistema multisseriado, qual seja, várias séries funcionando dentro de uma mesma sala mista (de meninos e meninas) - fato incomum para a época. Não se sabe qual era o número exato de salas de aula, bem como o de alunos atendidos. Em agosto de 1936, o jornal A Voz da Raça, p.4, faz referência a "mais de 200 alunos" nas escolas primárias e no curso de "Formação Social". Tudo indica que este curso franqueado pela FNB não era regular e constava de conferências a respeito de assuntos da atualidade, questões históricas, sociais e, principalmente, moral e cívica.

Quando investigou a relação entre raça e políticas públicas na área educacional no Brasil do período da Primeira República à era Vargas, Jerry Dávila concluiu que as políticas públicas educacionais - conduzidas ou apoiadas por intelectuais como Anísio Teixeira, Afrânio Peixoto, Fernando de Azevedo, Antônio Carneiro Leão e Edgar Roquette Pinto - tiveram um sentido duplo. Se, por um lado, criaram novas oportunidades no sistema escolar público como um todo, beneficiando alguns segmentos da população historicamente excluídos; por outro, reforçaram uma imagem negativa desses mesmos segmentos. Alunos pobres e de cor foram estigmatizados como doentes, problemáticos e limitados quanto ao potencial intelectual e cultural. "Este estudo", argumenta o historiador porto-riquenho,

...revela como as suposições raciais moldaram as intenções e os resultados da educação pública. [...] Os reformadores estudados aqui impregnaram as práticas que criaram com as suposições que possuíam sobre raça. Em consequência, as políticas públicas tendiam a operar para a desvantagem do crescente número de brasileiros de cor que entrou em contato com elas. (Dávila, 2006, p.39)

Dialogando com esse quadro de assimetrias raciais, as lideranças frentenegrinas começaram a forjar, ainda que de maneira judiciosa, um posicionamento crítico em face do sistema oficial de ensino, não só em relação ao caráter pouco universalista das políticas públicas educacionais, como ainda ao tratamento que os professores e a escola davam aos alunos negros, para não dizer quanto aos conteúdos escolares. Conforme nota Regina Pahim Pinto ( I993, p. 25 I), as lideranças frentenegrinas não realizaram críticas sistemáticas, porém revelaram que tinham uma noção de que as escolas da rede de ensino eram pouco receptivas ao alunado negro e que os professores tinham uma postura discriminatória. 
Cabe assinalar que a FNB não era a única organização do "movimento associativo dos homens de cor" que mantinha projetos educacionais naquele período. No Rio de Janeiro, o Centro Patriótico I 3 de Maio que surgiu, "graças aos esforços de um pugilo de homes de cor", já estava prestando "altos serviços à pátria e à nossa raça" em abril de 1930. Um dos "departamentos úteis desta nova agremiação carioca”, divulgava em 13/4/I 930, p.3, O Clarim d'Alvorada, "é a escola D. Gabriela Bensazoni Lage, que conta com um aprimorado corpo docente, e grande número de alunos e alunas. Ainda há pouco tivemos a grata notícia de um festival realizado na sede deste centro de cultura, sito à Rua Barão de S. Félix, 119". Infelizmente, não foram encontradas maiores informações dessa escola, mas como no final da matéria O Clarim d'Alvorada, um jornal publicado por e para os negros, felicita o seu "velho amigo Paiva", o idealizador do estabelecimento, e os "demais membros do Centro Patriótico 13 de Maio", tudo indica que a escola era destinada à "população de cor".

O mesmo jornal noticiou, em 13/5/1930, p.2, a instalação da Escola Luiz Gama, em Salvador, na Bahia: "Graças aos esforços do incansável e operoso professor Ascendino dos Anjos, a Associação Mãe Preta instalou a sua casa de ensino, para tanto, realiza-se hoje, na Praça 15 de Novembro, a primeira quermesse, em benefício da escola Luiz Gama". Também em Salvador, dezenas de negros de status profissional e social mais distintivo, conquanto na maioria modestos, organizaram a Sociedade Henrique Dias nos primeiros meses de 1937. Os seus líderes intelectuais eram um advogado e um antigo juiz, figura central do grupo. Segundo seus estatutos, a sociedade era "composta de pessoas brasileiras, sem distinção de cor" e tinha como propósito "pugnar pelo congraçamento e união entre pessoas de cores epidérmicas diferentes, desenvolver a educação, principalmente dos associados e suas famílias, dar-lhes assistência, realizar diversões, praticar esportes e comemorar datas cívicas". Depois de estruturar-se legalmente e fazer uma campanha de divulgação de seus ideais, a Sociedade Henrique Dias empreendeu o seu programa educativo e, graças a "uma pequena subvenção federal", abriu "uma modesta escola primária num bairro pobre" (Azevedo, 1996, p. I58-159).

Na cidade de Rio Grande (RS), o Centro Cultural Marcílio Dias foi erigido em 1936, com o objetivo de integrar-se na campanha de alfabetização oficial do governo, "atuando na escolarização dos homens de cor, tendo conseguido inaugurar pelo menos duas escolas, dentro de entidades carnavalescas negras, 
neste mesmo ano" (Loner, 2008, p.256). Raul Joviano Amaral - uma liderança afro-paulista - asseverava, em A Voz da Raça, de 23/6/I934, p.2, que as "sociedades beneficentes" ou os "clubes da gente de cor" conduziam o seu trabalho de "instrução" em condições de instalação precárias, ressentindo-se da falta de "apoio material"; as aulas eram ministradas em "salinhas acanhadas, com bancos toscos e mesas de caixão". Por essa razão, ele considerava necessário o "auxílio do governo".

Em 10 de novembro de 1937, com o apoio das Forças Armadas, Getúlio Vargas determinou o fechamento do Congresso Nacional e anunciou em cadeia de rádio a outorga de uma nova Constituição da República. A "polaca", como ficou conhecida, foi inspirada nas constituições fascistas da Itália e da Polônia. A partir de sua vigência, ficou praticamente regulamentada a ditadura do Estado Novo; foram suprimidos direitos civis e muitas das liberdades individuais. Em 2 de dezembro de 1937, um decreto aboliu todas as organizações dos movimentos sociais, declarando-as ilegais. Como consequência, a Frente Negra encerrou suas atividades, alguns meses antes das comemorações dos cinquenta anos da Abolição, em 1938.

Nessa primeira fase do movimento negro, é possível perceber como os vários grupos enfatizavam, se não priorizavam sua atuação na esfera educacional. Não se tratava, porém, de centralizar a ação no ensino superior, tampouco de reivindicar materiais didáticos alternativos, práticas de ensino multiculturais ou mesmo a inclusão da história da África nos programas curriculares. A prioridade era o ensino básico, particularmente a alfabetização do negro. E não por acaso. A alfabetização era tida como código de deciframento do mundo e, de acordo com o habitus vigente, tinha o poder de mudar a vida das pessoas. Como símbolo de distinção, fazia o negro se sentir bem, capaz, orgulhoso de si próprio e conectado com a gramática da civilização e do mundo moderno.

Acreditava-se que os negros, à medida que progredissem no campo educacional, teriam mobilidade social, seriam respeitados, reconhecidos e valorizados pela sociedade mais abrangente. A educação, nesse sentido, teria o poder de anular o preconceito racial e, em última instância, de erradicá-lo. Contudo, sua dimensão política não pode ser minimizada, quando não esquecida. Na Primeira República, a cidadania estava prevista na letra da Constituição, mas muitos negros não tinham meios de exercê-la, uma vez que a educação básica gratuita não era obrigatória e quem era analfabeto não podia votar. A 
afirmação da cidadania também fez parte do jogo. Alguns negros que passaram pelos bancos escolares não somente se apropriaram da leitura e escrita, como ainda fizeram delas armas importantes nos embates por uma sociedade mais justa, igualitária e democrática. $\bigcirc$ letramento, assim, deve ser igualmente apreendido nos seus contornos e significados políticos.

\section{Segunda fase (1937-1978)}

Ostado Novo (1 937-1945) caracterizou-se por ter suprimido os direitos democráticos e instaurado uma violenta repressão política no País, o que inviabilizou os movimentos contestatórios. Na verdade, alguns grupos negros sobreviveram e outros até vieram à tona no período - como a Associação dos Brasileiros de Cor, formada na cidade de Santos em 1938 -, patrocinando certas atividades cívico-culturais, mas, no geral, esses grupos eram de atuação paroquial, padecendo de uma articulação mais centralizada e representativa. Foi no crepúsculo do Estado Novo que o movimento negro organizado reapareceu plenamente revitalizado. A principal entidade nessa fase foi a União dos Homens de Cor - UHC -, fundada por João Cabral Alves, em Porto Alegre, em janeiro de 1943. Já no primeiro artigo dos estatutos, a entidade declarava que sua finalidade central era "elevar o nível econômico e intelectual das pessoas de cor em todo o território nacional, para torná-las aptas a ingressarem na vida social e administrativa do país, em todos os setores de suas atividades".

A UHC era constituída de uma complexa estrutura organizativa, porém o que chama a atenção é sua escalada expansionista. De acordo com João Cabral Alves, na edição do jornal Quilombo, de dezembro de 1948, p.3, a agremiação "possuía cerca de 284.000 negros inscritos", nessa data. É um desempenho extraordinário, embora deva ser referido com cautela, uma vez que esse número de afiliados não foi confirmado por outras fontes. De todo modo, é bastante significativo saber que uma entidade negra abriu sucursal ou teve representantes em 12 estados da federação: Rio Grande do Sul, Santa Catarina, Paraná, São Paulo, Rio de Janeiro, Minas Gerais, Espírito Santo, Bahia, Paraíba, Ceará, Maranhão e Piauí, e esteve presente em inúmeros municípios do interior. Para se ter uma noção mais exata, a UHC mantinha contato, em 1948, com 23 cidades, no Estado do Paraná e no do Rio Grande do Sul. Em linhas gerais, sua atuação era marcada pela promoção de debates na imprensa 
local, publicação de jornais próprios, serviços de assistência jurídica, médica e participação em campanhas eleitorais.

Outra importante área de atuação da UHC foi a educacional, pois já nos estatutos essa questão era pautada. Na sessão intitulada Nossas Reivindicações, ficou consignado: "Enquanto não for tornado gratuito o ensino em todos os graus, sejam admitidos brasileiros de cor como pensionistas do Estado, em todos os estabelecimentos de ensino superior do país, inclusive estabelecimentos militares" (apud Silva, 2005, p. 178). Tudo leva a crer que essa foi a primeira vez que uma organização do movimento negro reivindicou por parte do Estado brasileiro a adoção do que posteriormente ficou conhecido como políticas de ações afirmativas.

Em entrevista publicada no jornal Folha da Tarde, de Porto Alegre, em 3 I/I/1946, e novamente publicada em Quilombo, de dezembro de 1948, p.3, o presidente da UHC, João Cabral Alves, comunicava que um dos intuitos da organização era "manter moços e moças em cursos superiores, concedendoIhes roupa, alimentação etc., para que possam concluir os estudos". Embora sua ideia de assistência estudantil não tenha passado de uma declaração de intenções, é possível entrever como a UHC preocupava-se não apenas com o acesso, mas também com a permanência das "pessoas de cor" no ensino superior. A organização desenvolveu múltiplas campanhas de alfabetização no meio negro, e consta, inclusive, que ela conseguiu realizar o sonho de construção de uma escola em Porto Alegre.

Teatro Experimental do Negro - TEN - foi outro grupo importante dessa fase, embora sem a mesma penetração da UHC no seio da "população de cor". Estabelecido no Rio de Janeiro, em 1944, tinha Abdias do Nascimento como sua principal liderança. A proposta inicial era formar um grupo teatral apenas com atores negros, mas aos poucos o TEN adquiriu dimensão maior: foi ele que publicou o Quilombo, organizou conferências, congressos, promoveu concursos de beleza, inaugurou um centro de pesquisa e um museu. A educação não foi esquecida pelo grupo. Ao contrário, ela cumpriu um papel relevante como estratégia de enfrentamento do "preconceito de cor" (Müller, 1994). Em Quilombo, de janeiro de 1950, p. I I, uma liderança feminina do TEN, Maria Nascimento, discorria:

Pela educação é que havemos de conquistar igualdade moral, intelectual, cultural, artística, econômica e política. Quando todo negro souber ler e es- 
crever teremos dado o passo mais decisivo para a nossa própria recuperação. Enfim, educar e alfabetizar a população dos morros é uma forma de libertar e emancipar a gente negra. Porque a ignorância, o analfabetismo, é a forma mais terrível de escravidão.

Outra atividade levada a cabo pelo TEN foi justamente o curso de alfabetização, transcorrido entre outubro de 1944 e meados de 1946. Além de atacar o analfabetismo, um problema crônico da população negra, o curso visava proporcionar qualificação mínima para a participação do indivíduo na companhia teatral; afinal, era a necessário saber ler para decorar e encenar as peças. As aulas eram dadas em salas cedidas pela União Nacional dos Estudantes - UNE -, localizada no bairro do Flamengo. A coordenação do curso ficou nas mãos de Ironides Rodrigues, então estudante de Direito. Ministravam-se aulas de Português, Aritmética, Educação Moral e Cívica, História e Evolução do Teatro, alternadas com lições sobre o "folclore afro-brasileiro".

O TEN tinha noção dos problemas espinhosos com os quais os negros se deparavam na vida educacional, de modo que uma ativista do grupo, Guiomar Ferreira de Mattos, escreveu um artigo na revista Forma, de dezembro de 1954, também publicado em 1966 em outro veículo, apontando a presença de preconceitos raciais nos livros de "histórias instrutivas". No conto infantil Histórias maravilhosas, Humberto de Campos teria dito textualmente: "quando Deus pôs preto no mundo foi para tomar conta de filho de branco". Segundo Mattos, neste e noutros exemplos, "que seria fastidioso transcrever, e que qualquer pessoa achará, facilmente, em qualquer livro de histórias, estampa-se o preconceito, incutido, criminosamente, no espírito infantil".

Haroldo Costa, por seu turno, denunciava os "educandários" que não permitiam o ingresso de alunos "de cor". Essa prática igualmente incidiria nos estabelecimentos de ensino mantidos pela Igreja Católica e nas instituições oficiais: "ninguém desconhece os tremendos obstáculos que encontra o jovem negro quando se inscreve para prestar exame vestibular ao Instituto Rio Branco (Ministério das Relações Exteriores); ou no exame de admissão às escolas militares superiores". Costa, em Quilombo, de dezembro de 1948, p.4, argumentava que, mesmo vencendo a barreira da cor, o negro não era bem acolhido pelas escolas: 
Quando o diretor de um estabelecimento de ensino não pode proibir a entrada de um aluno negro no corpo discente do seu educandário, e a veia de seu preconceito entra em efervescência, ele move-lhe uma perseguição durante o decorrer do curso, promove seu alijamento psicológico, dificulta-lhe o que houver de mais banal; enfim, tudo faz crer que há uma campanha subterrânea e organizada visando anular as aspirações do negro que deseja estudar.

Independentemente de Haroldo Costa ter exagerado quando afirmou que existia uma espécie de conspiração dos diretores na rede de ensino para vetar ou obstaculizar o progresso educacional do contingente negro, o fato é que o "preconceito de cor" fazia parte do universo escolar, sob vários aspectos: desde professores e colegas de turma que tratavam os alunos negros de maneira diferenciada, passando pelo material didático, que veiculava uma série de estereótipos raciais, até a existência de um currículo de orientação eurocêntrica, o que enfraquecia a possibilidade de discussão da história e cultura afro-brasileiras.

Já em Duque de Caxias, cidade da Baixada Fluminense, o Centro Cultural José do Patrocínio atuou como mediador entre as demandas da população negra e os organismos governamentais, procurando, nas décadas de 1950 e 1960, prover os segmentos sociais subalternos das condições míninas para o exercício da cidadania por meio da escolarização, atendimento médico básico, assistência jurídica etc. Era estruturado em departamentos entre os quais se destacava o educacional, já que, segundo os estatutos da agremiação, era o responsável pela "criação e manutenção de cursos fundamentais: alfabetização, profissionais, universitários e outros como corte e costura, bordado, arte culinária, confecções artísticas". Entre a vontade e a realização é comum haver uma distância, de sorte que o Centro José do Patrocínio não conseguiu abrir cursos "universitários", mas investiu nas escolas de ensino fundamental, principalmente naqueles distritos mais pobres e distantes do centro da cidade. Em ofício encaminhado à Câmara Municipal de Duque de Caxias em 1970 , constava que a entidade mantinha quatro escolas e uma biblioteca (Pereira, 2006, p. 130$)^{5}$.

5. Eis a lista das unidades de ensino mantidas pelo Centro Cultural José do Patrocínio: Escola Típica Rural Santo Antônio, Escola São Jorge, Escola Barão de Lucena, Escola Profissional Dra. Fernanda Barcelos e Biblioteca Pública Dr. Nilo Peçanha. 
Nesse período surgiram organizações homônimas em São Paulo e Belo Horizonte. A Associação José do Patrocínio paulista devotava atenção especial à educação da comunidade negra ${ }^{6}$. A postura da Associação José do Patrocínio mineira, que veio a lume em 1951, era similar. Seu fundador, Antonio Carlos, era um ativista remanescente das organizações negras paulistas. Com criatividade e determinação, a Associação José do Patrocínio tinha como uma de suas finalidades propiciar "instrução" para as "pessoas de cor". Em sua sede, oferecia aulas de Português, Matemática; disponibilizava uma biblioteca de assuntos "afro-brasileiros" e realizava palestras periódicas (Gonçalves, 2000, p.338).

Em 1954, um grupo de afro-paulistas formou a Associação Cultural do Negro (ACN), visando conscientizar o negro sobre valores culturais do grupo, trabalhar para sua divulgação ressaltando a contribuição deles para a civilização brasileira, por meio de escolas, cooperativas, bibliotecas, cursos, atividades artísticas e desportivas. Localizada no centro de São Paulo, teve Geraldo Campos de Oliveira como primeiro presidente. Possuía uma Diretoria Executiva, presidida inicialmente por José Correia Leite, e um Conselho Superior. No seu auge, a ACN reuniu cerca de 700 afiliados. Publicou um jornal, O Mutirão, editou os "Cadernos de Cultura", patrocinou um ciclo de conferências batizado de "Os Encontros de Cultura Negra", montou uma biblioteca e articulou um projeto educacional ${ }^{7}$. Aliás, entre seus vários departamentos o mais importante foi o de "Educação e Cultura". De acordo com Regina Pahim Pinto, a ACN criou a Escola Cultural Áurea Brasileira no final da década de 1960, com o propósito de incentivar aqueles que desejassem cantar a música popular brasileira. A iniciativa, aprovada pela diretoria, nasceu do conjunto encarregado de animar as festas da agremiação. Mais de um ano depois, a escola enfrentava várias dificuldades para se efetivar, "tais como falta de instrumentos, local para ensaios, falta de cooperação. Este fato mostra que as instituições negras continuavam enfrentando problemas semelhantes com os que se depararam as suas an-

6. Uma nota do jornal Alvorada informava as atividades instrutivas oferecidas pela Associação José do Patrocínio: "A diretoria desta associação continua empregando todos os seus esforços para manter bem alto o padrão das suas atividades, principalmente, os cursos de alfabetização e de corte e costura" (Alvorada, São Paulo, 9/1945, p.4).

7. Plano de trabalho do Departamento de Educação e Cultura da Associação Cultural do Negro. Pasta 31 - Diretoria Executiva - Departamentos. Coleção Associação Cultural do Negro ACN. Acervo da UEIM/UFSCar. 
tecessoras" (Pinto, 1993, p.354). A ACN também teria aberto, na década de 1970, uma escola que ministrava cursos de "alfabetização e madureza", funcionando regularmente e abrigando cerca de "30 alunos (somente 2 eram brancos)". O curso de cultura negra era ofertado na medida do possível, por falta de professores (Moura, 1983, p.59).

Em Porto Alegre, a Sociedade Floresta Aurora e a Associação Satélite Prontidão desenvolveram algumas ações culturais de caráter pedagógico, procurando suprir a carência de letramento dos afro-gaúchos (Pereira, 2007). No que tange ao acesso ao ensino superior, a Associação Beneficente Pio XII, de São Paulo, foi provavelmente a precursora, no país, da defesa da criação de uma "Universidade Afro-Brasileira, onde preferencialmente estudem elementos da coletividade da raça negra" ${ }^{8}$. Em maio de 1962, a entidade já havia preparado a maquete da universidade e definido os terrenos de sua futura instalação.

A partir desse apanhado geral da segunda fase do movimento negro, verifica-se como os distintos grupos consideravam imprescindível o investimento na educação, ora por meios formais, ora informais. A educação básica continuou sendo o centro das preocupações, embora tenha sido nessa fase que surgiram as primeiras reivindicações relativas ao acesso do negro ao ensino superior e se esboçaram críticas a respeito do conteúdo preconceituoso dos materiais didáticos. Mas não se deve exagerar. Não se preconizavam, ainda, práticas de ensino multicultural, nem foram sistematizadas propostas pedagógicas calcadas na diversidade étnico-racial, sem esquecer que sequer foi ventilada a introdução da História da África nos programas curriculares.

A educação foi muitas vezes concebida em seu sentido polissêmico. Alfabetizar mobilizava a atenção de todos, afinal, tinha-se noção que o domínio do código da leitura e da escrita permitia abrir novos horizontes na vida do negro, elevando sua autoestima, seu capital simbólico, suas perspectivas de futuro e significando, concretamente, chance de novas oportunidades de trabalho e progresso social. A escolarização, assim, era tida como instrumento de qualificação do negro para o mercado de trabalho e de acesso ao mundo da cidadania, visto que o direito ao voto era uma prerrogativa exclusiva das pessoas

8. "Plano de integração social e cultural da coletividade negra no Brasil", I962. Pasta I8 - Diretoria Executiva - Correspondência. Coleção ACN. Acervo da Unidade Especial de Informação e Memória - UEIM-UFSCar. 
alfabetizadas. "É na escola", argumentava uma liderança afro-paulista9, em 0 Novo Horizonte, de 6/7/1949, p.2, "que obtemos certas vantagens favoráveis às lutas que travamos para o nosso bem-estar; de lá é que trazemos as testemunhas para o arrolamento dos processos de nossa causa". A escolarização conferia ao negro um cabedal que poderia ser canalizado para os embates no campo da cidadania. E, somando-se a tudo isso, ela era apreendida em seu potencial ético-cultural, na medida em que era tomada como uma importante, se não a principal arma na "cruzada" contra o "preconceito de cor".

\section{Terceira fase (1978-2003)}

A instalação da ditadura militar em 1964 provocou um significativo refluxo do movimento negro. Seus ativistas eram cerceados, estigmatizados e acusados de levantar um problema que supostamente não existia: o racismo no Brasil. Em virtude disso, a discussão pública sobre a questão racial ficou entorpecida. Isso não significa dizer que o movimento ficou totalmente desarticulado ou desapareceu da vida político-cultural do país; algumas vozes do protesto negro teimaram em não se calar. Na década de 1970, foram organizados o Centro de Cultura e Arte Negra - Cecan -, em São Paulo; a Sociedade de Intercâmbio Brasil-África - Sinba -, no Rio de Janeiro; o bloco afro llê Aiyê, na Bahia. Entretanto, o salto político do movimento aconteceu somente no final da década de 1970, no bojo da ascensão das lutas populares, dos movimentos sindicais, feministas, gays e estudantis. Um marco desse processo foi o nascimento do Movimento Unificado Contra a Discriminação Racial - MUCDR -, em 1978. Já nesse ano a organização aprovou o estatuto, carta de princípio e programa de ação. No ano seguinte promoveu seu primeiro congresso, reunindo delegados do Rio de Janeiro, Rio Grande do Sul, Espírito Santo, de São Paulo, Minas Gerais e da Bahia. Nesse Congresso seu nome foi alterado para Movimento Negro Unificado - MNU.

Conectado aos fluxos e refluxos do Atlântico Negro, o MNU investiu no retorno originário às "raízes" africanas como elemento fundante de qualquer

9. Ovídio dos Santos, referida liderança afro-paulista, encabeçou o "movimento afro-brasileiro de educação e cultura", tendo em vista arrecadar fundos para a construção do prédio da Escola Humberto de Campos, que ofereceria "curso primário e admissão ao ginásio", cf. O Novo Horizonte, de maio de 1949, p.5. 
prática política e cultural. Seus adeptos celebravam a "alteridade" e procuravam se desvencilhar de uma cosmovisão e um padrão estético ocidentais, usando trajes, adereços e estilos de penteado ditos afros e valorizando a "cultura africana": música, dança, literatura e até mesmo hábitos alimentares ${ }^{10}$. $\mathrm{Na}$ Carta de Princípios, a entidade conclamava pela "defesa do povo negro em todos os aspectos políticos, econômicos, sociais e culturais", por meio da conquista de, entre outras coisas, "maiores oportunidades de emprego; melhor assistência à saúde, à educação e à habitação; reavaliação do papel do negro na História do Brasil; valorização da cultura negra e combate sistemático à sua comercialização, folclorização e distorção"(MNU, 1988, p. 18). Com a perspectiva de combinar as variáveis "raça" e "classe" e unificar as hostes antirracistas em escala nacional, o MNU representou um novo momento na história do protesto afro-brasileiro, sendo que uma de suas preocupações era intervir na esfera educacional. Já no seu "Programa de ação", preconizava uma educação voltada para os valores e interesses do "povo negro e de todos os oprimidos" e se posicionava:

Contra a discriminação racial nas escolas, por melhores condições de ensino aos negros;

Pela reavaliação do papel do negro na História do Brasil;

Pela participação dos negros na elaboração dos currículos escolares em todos os níveis e órgãos culturais;

Pela inclusão da disciplina História da África nos currículos escolares;

Por mais vagas nas escolas públicas municipais, estaduais e federais;

Por mais bolsas de estudo;

Pela criação de escolas técnicas municipais profissionalizantes;

Pelo ensino público e gratuito em todos os níveis. (MNU, 1982)

Em Salvador, um grupo de mulheres - que depois contribuiu na fundação da seção local do MNU - empreendeu um trabalho de alfabetização de

10. Na verdade, o movimento de revalorização das origens africanas não foi uma exclusividade do MNU, mas fez parte de muitas outras associações afro-brasileiras. Como assevera Pinto (1993, p.468), a recuperação da história, por parte dessas associações, transcendia a diáspora e pretendia estender-se ao negro ainda na África. A exaltação das raízes africanas se fez cada vez mais presente, por meio das atividades culturais desenvolvidas ou propostas pelas associações. Observa-se esta ênfase nos conteúdos dos cursos oferecidos, como por exemplo, o de línguas africanas. 
adultos pelo método Paulo Freire, no bairro da Fazenda Grande do Retiro. Arani Santana, uma das integrantes do grupo, relata: "nós tínhamos consciência do que éramos capazes. Que era através da educação que poderíamos fazer alguma coisa" (apud Silva, 1988, p. I4). Contudo, a principal bandeira educacional desfraldada pelo MNU - e pelo conjunto do movimento negro brasileiro nessa fase - foi a da inclusão de conteúdos programáticos referentes à História da África e da cultura afro-brasileira nos currículos das escolas" !

O sociólogo e ativista negro Manoel de Almeida Cruz lançou, de forma pioneira, as bases de uma "pedagogia interétnica", visando à

...modificação de atitudes racistas através do processo educacional (escola, família, comunidade e meios de comunicação social) uma vez que o preconceito racial é transmitido por estes referidos processos e só através destes é que se pode transformar esse quadro. (Cruz, 1989, p. 13)12

Em 1979, o Núcleo Cultural Afro-Brasileiro, do qual Cruz fazia parte, organizou o 1 ' Seminário Experimental de Educação Interétnica, nas depen-

I I. A esse respeito, consultar, entre outras fontes, o Jornal do Movimento Negro Unificado, publicado a partir de 1989. No décimo ano de sua fundação, o MNU reuniu alguns documentos que balizaram a discussão interna da entidade e os publicou numa coletânea. Nela, a ativista Ana Célia da Silva - do Grupo de Trabalho Robson Silveira da Luz, do MNU da Bahia - foi a autora do documento no qual se registrava a importância dos estudos africanos nos currículos escolares: "Desde 1978 o MNU tem denunciado nos seus Congressos a distorção e ocultação do negro e seus valores na educação brasileira e tem exigido do Ministério da Educação e Cultura através de moções, a revisão do livro didático e a introdução da História da África nos currículos da história brasileira" (MNU, 1988, p.49).

12. No livro em que sistematizou as premissas da "pedagogia interétnica", Manoel de Almeida Cruz frisava, já na introdução, o significado desta nova concepção educacional: "A pedagogia interétnica significa na verdade uma resposta científica a nível teórico e metodológico na luta contra o racismo. Os estudiosos do preconceito racial apenas se limitaram a diagnosticar a existência do fenômeno, sem contudo imaginar um meio de eliminá-lo. Os progressos registrados no campo das ciências humanas, oferecem meios que possibilitam a invenção de instrumentos científicos para melhorar as relações interindividuais e intergrupais. Desta forma, a pedagogia interétnica está comprometida com a práxis, à medida em que propõe a modificação de comportamentos preconceituosos desfavoráveis ao negro e ao índio na estrutura global da sociedade brasileira. Esta disciplina também se reveste de um caráter interdisciplinar, buscando auxílio, de forma integrada, e sistematizada em vários campos do conhecimento humano, a exemplo da sociologia, da história, da psicologia, da antropologia, da biologia, da semiologia e da filosofia" (Cruz, 1989, p. I3). 
dências do Instituto Cultural Brasil-Alemanha, em Salvador. No ano seguinte, o núcleo promoveu o $2^{\circ}$ Seminário de Educação Interétnica. Como resultado, formou-se uma comissão que elaborou um currículo escolar "fundamentado na cultura negra", o qual foi adotado por uma escola "primária" no Vale das Pedrinhas, um bairro da periferia de Salvador. Várias atividades desse projeto pedagógico experimental procuravam incorporar a cultura afro-brasileira, por meio da música, da dança, da modelagem, do teatro e dos contos (Cruz, 1989, p.85).

Em 1982, o Centro de Cultura Negra do Maranhão - CCN - procurou diversificar seu programa de trabalho, assumindo a tarefa pedagógica como ferramenta de militância na conscientização da população de ascendência africana e no enfrentamento do racismo. Esse processo exigiu uma releitura da história do negro no Brasil e no Maranhão, o que deu origem a alguns documentos informativos - como Essa história eu não conhecia, texto elaborado e ilustrado especialmente para crianças e distribuído gratuitamente à população. A partir dessa postura o CCN buscou se articular com o sistema de ensino público, os estabelecimentos particulares e outras instituições de caráter educativo, tendo em vista abrir um amplo debate com alunos, professores e administradores escolares sobre a situação do negro (Souza, 1983). Em 1984, as entidades afrobrasileiras da Bahia pugnavam para inserir nos currículos das escolas públicas disciplinas calcadas na história e na cultura do negro. E, com esse desígnio, encaminharam às autoridades do Conselho Estadual de Educação um documento com o seguinte teor: "Nós, entidades negras da Cidade de Salvador e do estado, vimos, através deste, solicitar a V. Sxa. a inclusão no currículo de 1 ${ }^{\circ}$. Grau do nosso sistema de ensino, da disciplina 'Introdução aos Estudos Africanos'" (Cruz, 1989, p.81).

Paralelamente, Porto Alegre era palco do $1^{\circ}$ e o $2^{\circ}$ Encontro Nacional sobre a "Realidade do Negro na Educação", em 1984 e 1985, respectivamente. Com a redemocratização política em meados da década de 1980, iniciou-se uma tendência de atomização do movimento negro. Emergiram dezenas, talvez centenas, de grupos por todo o país. Além da introdução de disciplinas fundamentadas na história e na cultura do negro nos currículos escolares, grupos do movimento passaram a reivindicar do governo cursos para a qualificação de professores na prática de ensino multirracial e poliétnica, e uma revisão dos livros didáticos, a fim de eliminar deles a veiculação de idéias e imagens nega- 
tivas sobre o negro. Nesse contexto floresceram alguns projetos pedagógicos alternativos, como o do llê Aiyê, em Salvador, baseado no "patrimônio cultural africano" (Siqueira, 1996, p. I58).

Na década de 1990, o MNU entrou em crise e perdeu muito de sua força política. Simultaneamente, muitas das múltiplas organizações negras espaIhadas pelo país se especializaram, acentuando a tendência de incidir em frentes específicas. Um exemplo disso foi o Núcleo de Estudos Negros - NEN -, de Florianópolis. Embora criado com o propósito de militar em vários domínios, o grupo de ênfase às suas ações na educação, impulsionando debates, oficinas e encontros com educadores, negros e brancos. Em parceria com a Secretaria de Educação da cidade de Rio do Sul, em Santa Catarina, o NEN colaborou em um projeto com os professores da rede de ensino municipal durante nove meses, que incluía a discussão sobre a falta de referências bibliográficas e didático-pedagógicas acerca do negro, a necessidade de uma prática de ensino que levasse em conta a pluralidade racial, o reconhecimento de posturas discriminatórias no espaço escolar e as formas de combatê-las (Lima, 1997, p.87-88). Em Sergipe, a Casa de Cultura Afro-Sergipana lançou o projeto João Mulungu vai às Escolas ${ }^{13}$, animando atividades educacionais referentes à história e à cultura do negro em várias escolas da rede pública; sugerindo um trabalho pedagógico afro-centrado e produzindo materiais paradidáticos, para subsidiar a prática de ensino do professor em sala de aula.

Também apareceram organizações negras com caráter eminentemente educacional, como a Associação Afro-Brasileira de Educação Cultural e Preservação da Vida (1990), em São Paulo; a Cooperativa Steve Biko (1 992), em Salvador; o Educafro ( 1993), no Rio de Janeiro. Nessa fase, ocorreu outra mudança: o movimento negro assumiu de modo crescente a política de focalizar o acesso à universidade. Em razão disso, o dilema passou a ser como aumentar o índice de estudantes negros na universidade. Uma das alternativas experimentadas foi a de montar cursos pré-vestibulares para negros e carentes. Em São

13. João Mulungu é o nome de um legendário quilombola que, segundo os registros memorialísticos, notabilizou-se pela combatividade na luta contra a opressão escravista em Sergipe no século XIX. Sua trajetória foi adotada como símbolo de resistência por parte de um setor do movimento negro, particularmente pela Casa de Cultura Afro-Sergipana, que conseguiu chamar a atenção dos poderes públicos, a ponto de a Câmara de Vereadores de Aracaju ter outorgado a João Mulungu o título de herói negro, em 1992. 
Paulo, o primeiro deles foi o do Núcleo de Consciência Negra - NCN -, da Universidade de São Paulo - USP. Criado em 1994, o curso iniciou-se com uma turma de 140 alunos, dos quais no mínimo 70\% eram "negros ou mestiços". As aulas eram dadas de segunda à sexta-feira, no período noturno. Como a intenção não era tão-somente preparar os alunos para serem aprovados no vestibular, mas também conscientizá-los das questões raciais, nos sábados eram ministradas palestras por professores da USP ou convidados do movimento negro, no espaço de uma disciplina denominada Cidadania e Consciência Negra (Domingues, 2002, p.223).

A partir do final da década de 1990 e início da década posterior, as atenções do movimento negro foram canalizadas para o debate em torno das ações afirmativas, sobretudo na sua versão mais polêmica, o programa de cotas para negros nas universidades públicas. Um marco desse processo foi a aprovação pela Assembléia Legislativa do Estado do Rio de Janeiro, em 2002, da reserva de $40 \%$ das vagas para alunos negros no vestibular da Universidade do Estado do Rio de Janeiro - Uerj - e da Universidade Estadual do Norte Fluminense - Uenf

Não obstante, o fato de maior impacto referente ao tema do "negro e educação", no início desse terceiro milênio, foi a sanção por parte do Presidente da República da Lei n. 10.639, em 9 de janeiro de 2003, instituindo a obrigatoriedade do ensino da História e Cultura Afro-Brasileira nos estabelecimentos de ensino fundamental e médio. Em 10 de março de 2004, o Conselho Nacional de Educação aprovou as Diretrizes Curriculares Nacionais para a Educação das Relações Étnico-Raciais para o Ensino de História e Cultura Afro-Brasileira e Africana. Trata-se de medida inédita nos domínios da legislação federal. É verdade que a questão racial foi abordada durante os trabalhos da Assembleia Nacional Constituinte. Surgiu até um anteprojeto que enfatizava o papel central da educação, bem como o da escola como instituição que devia valorizar a diversidade, combater o racismo e todas as formas de discriminação, mas o documento final da Constituição Federal de 1988 não acolheu proposta de obrigatoriedade do estudo da cultura e História da África dos currículos nos três níveis de ensino. Já a Lei de Diretrizes e Bases da Educação Nacional LDB -, aprovada pelo Congresso Nacional em 1996, não conferiu qualquer tratamento específico à temática racial (Rodrigues, 2005). Portanto, a Lei n. 10.639 significou um avanço, e mesmo um divisor de águas ante a tradição 
homogeneizadora e monocultural das diretrizes do sistema de ensino ${ }^{14}$. Depois de décadas de ativismo, o movimento negro conseguiu, na terceira fase, que o Estado brasileiro atendesse uma de suas reivindicações precípuas na esfera educacional. Resta agora saber se a Lei n. 10.639 será implementada com êxito nas escolas ou não passará de letra morta. Isso, porém, só a história revelará.

\section{PARA CONCLUIR}

No pós-abolição, o negro "descobriu" progressivamente a importância da educação e o valor dos diplomas. Não somente descobriu como tomou a si iniciativas para agenciá-los sem depender da ação do Estado. Depois de décadas, essa situação mudou. Sem perder a perspectiva da autodeterminação, o negro passou a demandar políticas públicas e privadas para atacar as distorções raciais no campo educacional, como altos índices de evasão escolar, repetência e analfabetismo.

Não é sem motivos que a educação sempre esteve presente nos repertórios, projetos e empreendimentos das organizações afro-brasileiras, em suas diferentes modalidades, configurações e dimensões. Tanto como sinônimo de instrução (ou seja, de escolaridade), quanto no sentido amplo, incluindo as manifestações culturais, a educação ocupou um papel de destaque na estratégia de luta do movimento negro, sendo vista de diversas maneiras: como prérequisito de acesso à sociedade civilizada e moderna; como mecanismo capaz de equiparar os negros aos brancos, conferindo-Ihes oportunidades iguais no mercado de trabalho; como condição básica para a inclusão e consequente mobilidade social; como "instrumento de conscientização por meio do qual os negros aprenderiam a história de seus ancestrais, os valores e a cultura de seu povo, podendo a partir deles reivindicar direitos sociais e políticos, direitos à diferença e respeito humano" (Gonçalves, 2000, p.337).

14. Uma exceção a essa tradição homogeneizadora das diretrizes educacionais foi o aparecimento dos Parâmetros Curriculares Nacionais - PCNs -, em 1997. Distribuídos pelo Ministério da Educação, os PCNs traziam em um dos dez volumes a pluralidade cultural como tema transversal. Se não contemplou plenamente as expectativas de algumas lideranças do movimento negro, para as quais as complexas e multifacetadas questões étnico-raciais não deveriam aparecer - isso quando apareciam - tão-somente de forma oblíqua no trabalho pedagógico, representou mais um passo no contexto educacional que contribuiu para culminar na elaboração da Lei n. 10.639. 
Em outros termos, a educação sempre foi considerada o caminho mais eficaz, quando não a panaceia para a resolução de todos os males da população de ascendência africana. Parece, inclusive, que o movimento negro brasileiro tinha, de longa data, a percepção de que a educação está no centro das desigualdades raciais, assim como das desigualdades de renda, que diversas pesquisas contemporâneas vêm mostrando. A escolaridade é responsável pela maior parte das diferenças na mobilidade social entre brancos e negros e, como ponderou Telles (2003, p.238), "a educação é responsável por grande parte das variações raciais na desigualdade de ocupação nas maiores áreas urbanas do Brasil".

Na sua primeira fase de existência, o movimento negro no pós-abolição fomentou campanhas de conscientização junto à "população de cor", almejando conscientizá-la da importância do letramento; abriu pequenas escolas e cursos noturnos, privilegiando o ensino fundamental, sobretudo o trabalho de alfabetização. Além de instrumento de compreensão do mundo, a alfabetização demarcava a fronteira da cidadania formal no Brasil. Na segunda fase, o movimento negro ampliou seu raio de ação e, no que concerne a seus investimentos educacionais, montou algumas unidades de ensino, ofereceu cursos de alfabetização e coordenou projetos de cunho pedagógico, porém persistiu devotando especial atenção ao ensino fundamental.

Já na terceira fase, o movimento negro deu um giro copernicano. Se anteriormente produziu críticas ocasionais e pouco articuladas ao caráter eurocêntrico dos materiais didáticos e da grade curricular, não elaborando políticas a favor da incorporação de conteúdos programáticos específicos ou metodologias de ensino alicerçadas na pluralidade cultural, na terceira fase o movimento passou a reivindicar, sistematicamente, políticas públicas educacionais em benefício do segmento negro. Mais ainda. Procurou banir o eurocentrismo da educação e, em seu lugar, abraçou um projeto afrocentrado e multiculturalista, preconizando o direito à diferença, por meio da revisão da carga preconceituosa dos materiais didáticos, do desenvolvimento de práticas de ensino inclusivas e da adoção da História da África na grade curricular. Foi na terceira fase, portanto, que o movimento negro formulou projetos político-pedagógicos centrados nos postulados epistemológicos de uma educação multirracial e pluriétnica ${ }^{15}$.

15. Ao avaliar a aprovação da Lei n. 10.639, de 2003, Sales Augusto dos Santos comenta: "Os 
O movimento continuou, nessa fase, realizando trabalhos direcionados ao ensino fundamental - haja vista o atual clamor em prol de uma escola mais sensível à diversidade étnico-racial -, mas, aos poucos, ele passou a concentrar o olhar, também, no ensino superior, levantando aos píncaros a bandeira da democratização do acesso à universidade mediante as ações afirmativas - criação de cursos pré-vestibulares, de cotas raciais e mesmo de uma universidade específica ${ }^{16}$.

Em texto recente, Marcus Vinícius Fonseca (2007) denunciou a "invisibilidade" da população negra na historiografia educacional brasileira. Apesar de reconhecer que essa área de estudos e pesquisas transformou significativamente seus objetos, problemas e pressupostos teórico-metodológicos, enfatiza que continuou a reproduzir uma visão tradicionalmente cristalizada sobre os afrobrasileiros. Cabe uma indagação: se o processo de renovação da historiografia educacional não avançou no sentido de incorporar o negro, o que dizer dos esforços coletivos agenciados por esse segmento populacional na tentativa de articular a educação como instrumento de afirmação social? As linhas de estudos e pesquisas sobre história da educação não podem continuar negligenciando

movimentos sociais negros, bem como muitos intelectuais negros engajados na luta antiracismo, levaram mais de meio século para conseguir a obrigatoriedade do estudo da história do continente africano e dos africanos, da luta dos negros no Brasil, da cultura negra brasileira e do negro na formação da sociedade nacional brasileira" (Santos, 2005, p.34). Trata-se de uma avaliação equivocada, pois foi só a partir de sua terceira fase (1978-2003) que o movimento negro brasileiro passou a esposar a inclusão nos currículos escolares de uma disciplina específica para tratar das questões raciais. Portanto, essa reivindicação não tinha "mais de meio século" em 2003.

16. Em 2003, a Sociedade Brasileira de Desenvolvimento Sociocultural - Afrobras -, uma organização não governamental de São Paulo, inaugurou a Faculdade da Cidadania Zumbi dos Palmares, primeira instituição do gênero no Brasil, comandada por negros e comprometida com a questão da diversidade racial no ensino superior. Um dia depois da inauguração, o jornal Folha de S. Paulo, de 22/I I /2003, noticiou o evento: "Foi em 20 de novembro de 1695 que o líder negro Zumbi foi barbaramente morto, esquartejado e teve sua cabeça exposta no centro de Olinda como prova da destruição do Quilombo dos Palmares. Mas foi ontem, 308 anos depois, em São Paulo, que o símbolo de uma resistência de quase cem anos virou nome de faculdade, a primeira do Brasil a priorizar a inclusão de afrodescendentes no ensino de nível superior. A iniciativa é continuação do projeto Mais Negros nas Universidades, da Afrobras. [...] $\bigcirc$ primeiro curso a ser aberto em 2004 é Administração (a mensalidade é de $\mathrm{R} \$ 240,00$ ). A turma deve abrigar 120 alunos (até 50\% das vagas são destinadas àqueles que se declararem pretos e pardos)". 
o tema da resistência negra, especialmente nesse momento singular, em que o Estado e a sociedade civil no Brasil estão enfronhados no debate acerca da solução das desigualdades raciais.

Que os dramas educacionais enfrentados por José Correia Leite e Lima Barreto no início do século $X X$ não se repitam na vida das próximas gerações de afro-brasileiros.

\section{REFERÊNCIAS BIBLIOGRÁFICAS}

ANDREWS, G. R. O Protesto político negro em São Paulo (I 888- | 988). Estudos AfroAsiáticos, Rio de Janeiro, n.21, p.27-48, 1991.

AZEVEDO, T. As Elites de cor numa cidade brasileira: um estudo de ascensão social \& classes sociais e grupos de prestígio. 2.ed. Salvador: EDUFBA, 1996.

BARRETO, A. H. de. L. Vida urbana. São Paulo: Brasiliense, 1956.

BRASIL. Ministério da Educação. Diretrizes Curriculares Nacionais para a Educação das Relações Étnico-Raciais e para o Ensino de História e Cultura Afro-Brasileira e Africana. Brasília, 2005.

CRUZ, M. de A. Alternativas para combater o racismo segundo a pedagogia interétnica. Salvador: Núcleo Cultural Afro-Brasileiro, 1989.

DÁVILA, J. Diploma de brancura: política social e racial no Brasil (1917-1945). São Paulo: Unesp, 2006.

DOMINGUES, P. Ações afirmativas: a saída conjuntural para os negros na educação. In: PORTO, M. do R. S. et al. (orgs.) Negro, educação e multiculturalismo. São Paulo: Panorama, 2002. p.221-234.

A Insurgência de ébano: a história da Frente Negra Brasileira (1931 - 1937). São Paulo, 2005. Tese (dout.) FFLCH-USP. A Nova abolição. São Paulo: Selo Negro, 2008.

FELIX, M. As Práticas político-pedagógicas da Frente Negra Brasileira na cidade de São Paulo (1931 - 1937). São Paulo, 200I. Dissert. (mestr.) PUC.

FONSECA, M. V. A Educação dos negros: uma nova face do processo de abolição da escravidão no Brasil. Bragança Paulista: Edusf, 2002.

AArte de construir o invisível: o negro na historiografia educacional brasileira. Revista Brasileira de História da Educação, n. I 3, p. I I-50, 2007. 
FRAGA FILHO, W. Encruzilhadas da liberdade: histórias de escravos e libertos na Bahia (|870-19|0). Campinas: Unicamp, 2006.

GONÇALVES, L. A. O. Negros e educação no Brasil. In: LOPES, E. M. T. et al. 500 anos de educação no Brasil. 2.ed. Belo Horizonte: Autêntica, 2000. p.325-346.

HASENBALG, C.; SILVA, N. do V. Raças e oportunidades educacionais no Brasil. Estudos Afro-Asiáticos, Rio de Janeiro, n. 18, p.73-91, 1990.

LEITE, J. C. ...E disse o velho militante José Correia Leite: depoimentos e artigos. Organização e textos de Cuti. São Paulo: SMC, 1992.

LIMA, I. C. Ações educacionais em Santa Catarina. In: BARBOSA, L. M. de A.; SILVA, P. B. G. e (orgs.) O Pensamento negro em educação no Brasil: expressões do movimento negro. São Carlos: Ed. UFSCar, 1997. p.8I-88.

LONER, B. A. A Rede associativa negra em Pelotas e Rio Grande. In: SILVA, G. F. da; SANTOS, J. A. dos; CARNEIRO, L. C. da C. RS negro: cartografias sobre a produção do conhecimento. Porto Alegre: EDIPUCRS, 2008. p.246-26I.

MATTOS, G. F. de. O Preconceito nos livros infantis. In: NASCIMENTO, A. do. (org.) Teatro Experimental do Negro: testemunhos. Rio de Janeiro: GRD, 1966. p. I36-139.

MOURA, C. Brasil: raízes do protesto negro. São Paulo: Global, 1983.

MOVIMENTO NEGRO UNIFICADO. 1978-1988: 10 anos de lutas contra o racismo. São Paulo: Confraria do Livro, 1988.

Programa de Ação. Belo Horizonte, 1982.

MÜLLER, L. S. As Contas do meu rosário são balas de artilharia: irmandade, jornal e sociedades negras em Porto Alegre (1 889- 1920). Porto Alegre, 1999. Dissert. (mestr.) PUC-RS.

MÜLLER, R. G. Teatro Experimental do Negro: projeto político-pedagógico. Educação \& Sociedade, Campinas, n.49, p.559-576, 1994.

PEREIRA, J. G. Os Negros e a construção da sua cidadania: estudo do Colégio São Benedito e da Federação Paulista dos Homens de Cor de Campinas (|896-19|4). Campinas, 200 I. Dissert. (mestr.) FE-Unicamp.

PEREIRA, L. R. B. P. Cultura e afrodescendência: organizações negras e suas estratégias educacionais em Porto Alegre ( $872-2002)$. Porto Alegre, 2007. Tese (dout.) PUC-RS.

PEREIRA, S. G. M. Vozes afro-caxienses: ecos político-culturais dos movimentos de resistência negra em Duque de Caxias (1949-1968). Vassouras, 2006. Dissert. (mestr.) Universidade Severino Sombra. 
PERES, E. Sob(re) o silêncio das fontes... A trajetória de uma pesquisa em história da educação e o tratamento das questões étnico-raciais. Revista Brasileira de História da Educação, n.4, p.75-102, 2002.

PINTO, R. P. O Movimento negro em São Paulo: luta e identidade. São Paulo, 1993. Tese (dout.) FFLCH-USP.

RODRIGUES, T. C. Movimento negro no cenário brasileiro: embates e contribuições à política educacional nas décadas de 1980 e 1990. São Carlos, 2005. Dissert. (mestr.) Universidade Federal de São Carlos.

SANTOS, S. A. dos. A Lei n. 10.639/03 como fruto da luta anti-racista do Movimento Negro. In: BRASIL. Ministério da Educação. Secretaria da Educação Continuada, Alfabetização e Diversidade. Educação anti-racista: caminhos abertos pela Lei Federal n. 10.639/03. Brasília, 2005. p.21-37.

SILVA, A. C. da. Estudos africanos nos currículos escolares. In: MOVIMENTO NEGRO UNIFICADO. 1978-1988: 10 anos de lutas contra o racismo. São Paulo: Confraria do Livro, 1988. p.48-51.

SILVA, A. M. P. da. Aprender com perfeição e sem preconceito: uma escola para meninos pretos e pardos na Corte. Brasília: Plano, 2000.

SILVA, J. C. da. História de lutas negras: memórias do surgimento do movimento negro na Bahia. In: MOVIMENTO NEGRO UNIFICADO. 1978-1988: 10 anos de lutas contra o racismo. São Paulo: Confraria do Livro, 1988. p.7-19.

SILVA, J. da. União dos Homens de Cor (UHC): uma rede do movimento social negro, após o Estado Novo. Rio de Janeiro, 2005. Tese (dout.) Uerj.

SILVA, P. B. G. e. Movimento negro e educação. Revista Brasileira de Educação, São Paulo, n. I5, p. 134-158, 2000.

SIQUEIRA, M. de L. Ilê Aiyê: uma dinâmica de educação na perspectiva cultural afro-brasileira. In: MUNANGA, K. (org.) Estratégias e políticas de combate à discriminação racial. São Paulo: Edusp, 1996. p.| $57-165$.

SOUZA, C. L. V. de. Uma experiência como movimento social: Centro de Cultura Negra do Maranhão. Estudos Afro-Asiáticos, Rio de Janeiro, n. 8/9, p.37-52, 1983.

TELLES, E. Racismo à brasileira: uma nova perspectiva sociológica. Rio de Janeiro: Relume Dumará, 2003. [Trad.: Nadjeda Rodrigues Marques, Camila Olsen]

Recebido em: março 2007

Aprovado para publicação em: julho 2007 